\title{
Static and fatigue strength of oil palm wood used in furniture
}

\begin{abstract}
A study was undertaken to evaluate the edge-wise static and fatigue strengths of oil palm wood, as the material is being promoted for furniture applications. The static and fatigue tests were conducted using a 3-point bending test-rig. The fatigue test was carried out at selected stress levels that corresponded to specific percentages of the material's ultimate strength (Modulus of Rupture (MOR)). The results showed that Oil Palm Wood (OPW) had a much lower bending and ultimate strength compared to the other common furniture wood materials, due to its lower density. In terms of it's the fatigue strength although oil palm wood showed lower fatigue resistance compared to the other common wood materials used in furniture. The result found that fatigue life of OPW amounted to over 1 million cycles when the stress level was $30 \%$ of the MOR for OPW, but decreased to 203,000 cycles for OPW at a stress level of $50 \%$. On this account, the allowable design stresses for the OPW could be set at $40 \%$ of its MOR. Although, the study showed that OPW does not perform as well as other common wood materials used in furniture, with a larger safety factor, OPW can be successfully used as an alternative furniture material.
\end{abstract}

Keyword: Load; Cyclic; Static; Wood; Furniture 